Annals of Phytomedicine, Volume10, Special Issue2 (COVID-19): S98-S110, 2021

\begin{tabular}{l|c|c|c|c|} 
DOI: http://dx.doi.org/10.54085/ap.covid19.2021.10.2.11 \\
Annals of Phytomedicine: An International Journal \\
http://www.ukaazpublications.com/publications/index.php \\
Print ISSN : 2278-9839
\end{tabular}

Review Article : Open Access

Special Issue2 (COVID-19)

\title{
Potential herbs as therapeutic agents for COVID-19: In silico studies
}

Nupur Mehrotra , Sara A. Khan and Kaustubh Jadhav

Department of Biochemistry, SVKM's Mithibai College of Arts, Chauhan Institute of Science and Amrutben Jivanlal College of Commerce \& Economics (Autonomous), Affiliated to University of Mumbai, Vile-Parle (West), Mumbai-400056, India

\section{Article Info}

Article history

Received 20 October 2021

Revised 6 December 2021

Accepted 7 December 2021

Published Online 30 December 2021

\section{Keywords}

COVID-19

In silico

Binding energy

Molecular docking studies

Spices and herbs

\begin{abstract}
Across 218 countries, since March 2020, severe acute respiratory syndrome coronavirus 2 (SARS-CoV2) infection has been a reason for concern. Doctors as well as researchers, stand together to find a treatment for this pandemic. The virus attaches to the host cells via transmembrane spike glycoprotein. The glycoprotein has affinity for human angiotensin-converting enzyme 2 and is dimeric. Thus, the virus attaches to the ACE receptors through the receptor-binding domain (SARS-CoV-2 RBD Spro). Further, the main protease (Mpro), a chymotrypsin-like protease (3CLpro), plays a critical role in post-translational modifications, thereby affecting viral survival. Thus, targeting these viral markers can not only block the fusion with host cells, but also affect replication of the virus. Ancient civilizations have been using plants, herbs as well as spices for their medicinal values as antiviral, antiinflammatory, antipyretic, antimicrobial and many more. The rich array of phytochemicals in these spices endows them with these beneficial properties, and hence they are largely being looked as agents for therapeutic use. However, the journey from laboratory for drug development is a time-consuming process as it starts from trying to identify the major therapeutic component to its pre-clinical studies, clinical and then its marketing as a drug. In the current pandemic where loss of human life has been in millions, a faster and more efficient modality like in silico studies can help escalate this search for a therapy thereby saving mankind. This study is a comprehensive review on results of in silico approaches conducted in near future in an attempt to evolve an ideal therapeutic candidate for ending the pandemic. Results of research conducted on phytochemicals from medicinal and aromatic plants as potential therapeutic candidates using tools of bioinformatics and computational modelling are hereby discussed.
\end{abstract}

\section{Introduction}

Till December 2021, SARS-CoV-2, the causal agent of COVID-19 has inflicted more than 27.8 crores people worldwide, leading to the fatality of more than 53.9 lakhs people globally. WHO has declared COVID-19 as the Public Health Emergency of International Concern (PHEIC) signifying the fact that this pandemic seeks harmonized comprehensive retort in all therapeutic facets (Gowrishankar et al., 2021). This pandemic hasled to a global socioeconomic catastrophe. Till today, there are no active therapeutic treatments, and the planning for vaccine distribution still embodies a major contest for developing countries, contributed by the specific requirements of vaccine transportation and storage (Nadia et al., 2021). Presently, the different vaccines developed include the one developed by Pfizer (New York, NY, USA), University of Oxford and Astra Zeneca's AZD1222; BNT162, BioNTech (Mainz, Germany), and mRNA-1273, developed by Moderna Inc. (Cambridge, MA, USA).

Recently established biotechnological tools as monoclonal antibodies and recombinant proteins are also under investigation as therapeutic

\section{Corresponding author: Dr. Nupur Mehrotra}

Head, Department of Biochemistry, SVKM's Mithibai College of Arts, Chauhan Institute of Science \& Amrutben Jivanlal College of Commerce and Economics (Autonomous), Vile-Parle (West), Mumbai-400056, Affiliated to University of Mumbai, India

E-mail: nupur.mehrotra@mithibai.ac.in

Tel.: +91-022-42339049

Copyright (c) 2021 Ukaaz Publications. All rights reserved.

Email: ukaaz@yahoo.com; Website: www.ukaazpublications.com agents (Jahanshahlu and Rezaei, 2020). As per Twomey et al. (2020), the most appropriate approach to combat COVID-19 is to redesign the available pharmacological modalities. This is an effective strategy that saves time, money and lives and investigators throughout the world are at work towards the development of effective therapeutic strategies (Sankar et al., 2021). According to the study of Benarba and Pandiella (2020), many of the botanical plants found in Indian subcontinent have been found to exhibit antiviral and anti-inflammatory properties. Some of these phytocompounds have been investigated to be effective against COVID-19 as well (Murugan et al., 2020).

The main reason for disorders related to SARS-CoV2 leading to COVID-19 being declared a pandemic is its contagious nature with mortality rates being high (Coronavirus Update, https:// www.worldometers.info/coronavirus/, 2021). With treatment modalities being limited even 1.5 years into the pandemic, the need of the hour is to try to find out tactics that are effective for the viral outbreak. Drug discovery involves handling and interpretation of huge and complex data and so the journey from the bench to the market is a long-drawn process of 12-15 years, besides being an expensive one. The need for elucidating newer therapeutic options which are a reliable and effective, has led to the application of databases to identify active pharmaceutical components. This fasttrack modality needs to be adopted so as to hasten the process of identifying possible remedies which can be used as targets to proceed to the clinic and finally reach the customers at large. Here comes the utility of computational modelling for ligand-receptor 
interactions, for drug discovery and development. The use of these tools has been employed over the years to hasten and augment the pharmacologic discovery progression (Yang et al., 2012).

Drug designing owes its origin to the understanding of pharmacokinetics and pharmacodynamics of a molecule being affected by its structure. One of the earliest studies on establishing this relationship was put forward by Meyer (1899) and Overton (1901), who suggested the Lipoid theory to explain cellular depression, which related depressant action with lipid solubility. Hansch $(1964,1972,2002)$ made pioneering efforts in using mathematics and statistics to draw quantitative relations between structure and activity. This lead to the birth of the field of quantitative structure-activity relationships (QSARs), progressing to the use of computer graphics for molecular modelling. In the last few decades, computer scientists have evolved as major contributors towards drug discovery and pharmacology. In current times, chemistry-biology-informatics have evolved and contributed to enriching the field of pharmacology. Thus, computational pharmacology or in silico methods have not only improved the drug discovery procedure and put it on a fast-track saving both time and money too (Swaan and Ekins, 2005).

The targets on the causative agent can be any of the biomolecules on or within the agent like the nuclear material as DNA or RNA or an array of proteins comprising enzymes, receptors or even transporters. Such targets need further validation, either at cellular or molecular levels so as to delineate their relevance to the known disease with sufficient level of 'confidence' (Taft et al., 2008). Next the validation of the target is facilitated through identification of modulators, inhibitors, or antagonists and this process is termed lead identification. This is mediated through designing and development of suitable assay procedures to complete the study for target identification and its validation. With the target validated, complementary molecules, which could be natural or synthetic are identified as per their structure, with the potential of binding to the target, thereby completing the process of lead identification. Progressing further the lead molecule is optimized, through studies as physiochemical characterization. Techniques as quantitative structure activity relationships (QSARs) and high throughput screening (HTS) coupled with combinatorial chemistry lead to generation of multiple new chemical entities (NCEs). These processes are not quite viable due to the cost being high as the process involves expensive instrumentation and costly reagents. The utility of computer assisted techniques or in silico studies provides not only pace to the drug discovery process but is economical along with being quite viable. Thus, through in silico studies an array of molecules along with their analogues can be designed to suit the target specificities and hasten the early stages post which preclinical and clinical phases only need to be conducted for the drug to be marketed (Smith, 2003; Green and Segal, 2014; Etkins et al., 2014).

\section{Methods for in silico studies}

The field of drug discovery via in silico drug design is extensive and has multiple approaches modern tools as QSAR structure-based design, bioinformatics, cheminformatics, combinatorial library design, biological and chemical databases (Figure 1).

\section{Homology modelling}

Homology modelling, or comparative modelling uses the amino acid sequence and generates an atomic resolution model of the 'target' protein which complements an investigational 3D structure of an associated homologous protein or 'template' (Marti et al., 2000). Thus, it identifies structures from its database and maps for resemblance with the query sequence. It has been observed that even during evolution the protein structure has remained largely conserved over DNA sequences (Park et al., 2008). Software tools create 3D structure based on the known template's 3D structures. Amongst the popular tools used in homology modelling are the modeller along with the SWISS-model repository, the database of protein structures (Richard, 2005).

\section{Virtual high-throughput screening (VS)}

The computational approach of virtual screening requires utilization of chemical structures libraries, which are assessed for binding potential of target molecules-largely protein receptors and enzymes (Wadood et al., 2013). Its focus is thus to resolve the query of screening amongst $10^{16}$ possible compounds and short-listing the ones that can be synthesised and evaluated. VS centres on designing and boosting targeted combinatorial libraries and enriching the from compound repositories. It is not only cost-effective than highthroughput screening but also time saving.

\section{Molecular docking}

Interaction networks or molecular modelling docking envisages the favoured orientation between a ligand and a receptor or target protein that forms a stable complex on binding to each other (Soloman, 2008). It thus facilitates the recognition and optimization of potential candidates for drugs by studying the possible molecular interactive binding between the ligand and the target. Thus, virtual high-throughput screening (HTS) studies involves generation of several ligand conformations and orientations and the ones with most efficient binding are selected (Perdo, 2010). Widely used tools include DOCK, Auto Dock, ArgusDock, FTDock, FRED and eHITS.

Hologram quantitative structure activity relationship (HQSAR)

QSAR methods depict the association of structural and biological activity. In Hologram QSAR, correct 3D information of ligands is not a pre-requisite and the molecule is split into molecular finger prints and the frequency of occurrence of such molecular fragments is observed. The size of the fragment decides the upper and lower limit of the fragments, though the general length is 4 to 7 atoms (Cramer et al., 1988).

Comparative molecular field analysis (CoMFA) and comparative molecular similarity indices analysis (CoMSIA)

A constructive new tool for QSAR studies is CoMFA or 3D QSAR method. $\mathrm{C} \log p$ values of the ligands are obtained through this technique which give an insight into steric as well as electrostatic hindrances along with the solvent repellent constraints (Cramer et al., 1988). CoMSIA is generally used to pinpoint the shared characteristics between ligand and receptor for proper binding. Besides the steric and electrostatic characteristics, it also gives insight into hydrogen bond donor and acceptors donor groups and hydrophobic interactions present (Kurogi and Guner, 2001). 


\section{D pharmacophore mapping}

A pharmacophore is the 3D arrangement of functional groups on a lead molecule which is the active site of an enzyme or ligand. This leads to rapid identification of lead compounds for a chosen target and also accelerates the knowledge on ligand-receptor interaction. With identification of the pharmacophore, via database search tools, other novel compounds having structure similar to the pharmacophore are identified. Currently, used search algorithms are advanced to ascertain and optimize efficiently the lead target from combinatorial libraries using virtual high-throughput screening (Meyer et al., 2000).

\section{Microarray analysis}

DNA technology or DNA microarrays are prepared on chips/slides having many markings and each comprises of a gene with known DNA sequence. These DNA sequences function as probes to detect gene expression. Effective analysis of transcriptome or the mRNA transcripts expressed by a gene, is thus completed. This facilitates making the appropriate choice of the lead molecule for drug development (Du et al., 2021).

\section{Conformational analysis}

Such tools facilitate evolving 3D structures via use of calculation on the basis that the molecule should be in a stable conformation with minimum energy configurations. The study involves use of interaction networks to compare the complementarity between the ligand and the receptor such that the association is most energetically favourable (Yang et al., 2021).

\section{Monte Carlo simulation}

Statistical mechanics is used in Monte Carlo simulation which gives an output of multiple conformations through computer simulation and suggests the ideal one considering the structure and thermodynamics. Another modification of the technique makes use of variable temperatures to simulate annealing which enhances ligand binding to receptor (Tuckerman and Martyna, 2000).

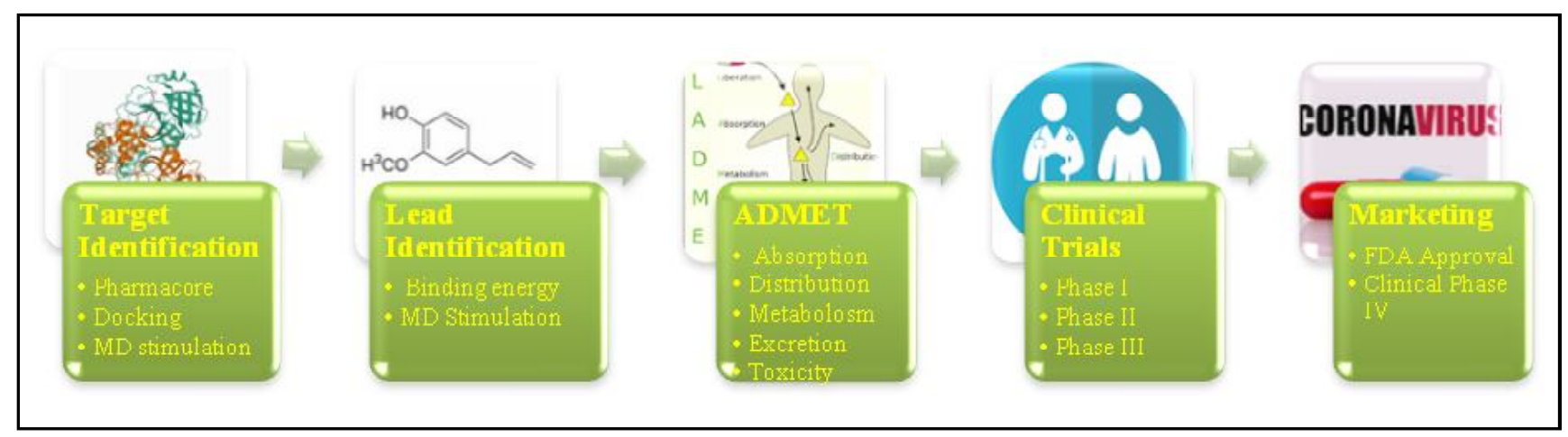

Figure 1: Drug discovery mediated by in silico studies.

This current study is focussed on use of in silico tools to facilitate the discovery of lead targets and lead molecules from natural plant resources and nutraceuticals with the potential of being developed as remedies for the SARS-CoV-2.

\section{Potential herbs}

\subsection{Allium sativum (Garlic)}

Allium sativum (Garlic) belongs to the Liliaceae family. It has been used as a therapeutic agent since time immemorial (Singh et al., 2020). Garlic has a high nutritive value and is known to have extensive health benefits (Alam et al., 2016). Garlic is rich in sulphur containing compounds, namely allicin, allinin and its derivatives and derived organosulfur compounds. To name a few important phytoconstituents, S-allyl cysteine sulfoxide (alliin), ajoenes (E- and Zajoene), vinyldithiins (2-vinyl-(4H) -1,3-dithiin, 3-vinyl-(4H)-1,2dithiin), and diallyl (di and tri) sulfide S-allyl-cysteine, S-allymercapto cysteine, and nacetylcysteine (El-Saber Batiha et al., 2020).

One of the phytocompound present in A. sativum is allicin (diallyldithiosulfinate) that has antifungal and antiviral activities. According to the study of Gebreyohannes and Gebreyohannes (2013), the increasing order of virucidal activity of garlic phytoconstituents was due to methyl allyl thiosulfanate, allicin and ajoene. The extract has been observed to be active against the H1NI cell culture of influenza virus $\mathrm{A}$, by inhibiting virus attachment and proliferation in cell culture (Mehrbod et al., 2009). The extract also demonstrates effectiveness against infectious bronchitis virus (IBV-a coronavirus) (Shojai et al., 2016).

Amongst the phytochemicals in garlic, 7 compounds showing decreasing order of binding energies with major protease 6LU7 were S-allylcysteine sulfoxide (Alliin) > S-propyl L-cysteine, >Sallylcysteine $>\mathrm{S}$-ethylcysteine> S-allylmercaptocysteine Smethylcysteine> S-propyl cysteine (Pandey et al., 2021). Thuy et al. (2020), characterised the essential oils, namely; allyl- disulfide, and trisulfide, diallyl trisulfide and tetrasulfide and 2-propenyl propyl, and these showed high binding affinity towards Mpro as well as towards the ACE2 receptor with low docking score energies. Thus, these essential oils can be promising candidates as they not only prevent infection as the virus cannot bind to the ACE receptors on the host cells but it also inhibits the molecular mechanisms of DNA replication and RNA transcription through Mpro. Mahmoud et al. (2020), too studied sulphur containing phytochemicals in garlic and have found docking scores ranging from -4.4 to -3.4 . They found that the binding sites with Mpro were mainly, Arg 188 $(2.14 \alpha)$, Thr190 (1.92 $\alpha)$, Gln192 (2.34 $\alpha)$, and Glu166 (1.85).

Garlic can slow the development of cytokine storm as it downregulates close to 36 genes that mediate transcription of a majority of inflammatory cytokines, as the essential oils activate Nrf2 which facilitates the decrease in secretion of cytokines (McCord et al., 2020). 
Another factor contributing to allicin being an inhibitor of Mpro in SARS-CoV-2, is that it causes dual S-thioallylation of Cys-85/ Cys-156 residue in Mpro and Cys-145 of the compound (Shekh et al., 2020).

\subsection{Azadirachta indica (Neem)}

Neem belongs to a family Meliaceae found in Africa and Asia. Neem is considered to be a medicinal plant as it exhibits properties for treating diverse infectious and chronic diseases (Oladela et al., 2020). Each part of this plant, viz., seeds, leaves, bark and roots possesses medicinal potential. As per the findings (Yerima et al., 2012; Akin-Osanaiya et al., 2013; Naik et al., 2014; Basir and Shailey, 2012; Singh et al., 2014) and Shrivastava and Swarnkar (2014) bioactive compounds in neem have proven to exhibit anticarcinogenic, antidiabetic, antiplasmodial, antimicrobial, antifungal, anti-inflammatory, and antiviral (Tiwari et al., 2010; Sher et al., 2018). Ethanolic extracts of azadirachta have exhibited antimicrobial properties along with free radical scavenging potential (Alzohairy, 2016). According to the studies done by Tiwari et al. (2010), 50 to $100 \mu \mathrm{g} / \mathrm{ml}$ of neem bark exhibits inhibitory activity on HSV-1. Inhibition of glycoprotein mediated cell-to-cell fusion of HSV-1 demonstrated the potential antiviral activity of neem bark. Also leaf extract of neem has been selected as virucidal agent against coxackievirus B-4 by interfering in early stages of replication (Badam et al., 1999).

Phytochemicals which hold analogy to limonoids and triterpenoids were found to possess activity against SARS-CoV 2 protein targets, $v i z$. , 3CLpro, PLpro, SGp-RBD, RdRp and ACE2 (Vardhan and Sahoo, 2020). The relative binding free energy of azadirachtin $H$ with $S$ RBD-ACE2 and S-RBD was calculated and found to be $129 \pm 19$ and $152 \pm 29 \mathrm{~kJ}$ mol 1, respectively (Daniel et al., 2021). Nimbolin A, nimocin, and cycloartanols, from neem effectively bind to envelope as well as the membrane glycoproteins of SARS-CoV-2, and thus inhibits its docking to host cells (Borkotoky and Banerjee, 2020). Further, Aljindil (2012) and Venugopalan et al. (2011), observed immunomodulatory effects by enhancing the immune cells from components from neem seeds and leaves. Molecular docking of neem compound with SARS-CoV-2 proteins $M$ and E suggested that these components have ability to prevent viral assembly leading to reduced propagation of viruses. This finding could propose that combination (Lim et al., 2021) of viral replication and assembly inhibitors would be better regimen for treatment modality.

\subsection{Curcuma longa (Turmeric)}

A member of the Zingiberacea family, turmeric (Curcuma longa) is found to be present naturally in India and Southeast Asia (Singh et al., 2021). As reported by Omosa et al. (2017), rhizomes of $C$. longa are rich in many secondary metabolites, which includes steroids, curcuminoids, polyphenols and sesquiterpenes as the predominant active therapeutic components. Since ancient times, the polyphenol of turmeric, curcumin has been exploited. Several studies have reported the anticancerous and anti-inflammatory properties of curcumin. The added advantage associated with curcumin is that there are no adverse effects associated with its administration and the US regulatory body, FDA has categorized curcumin as "Generally Recognized as Safe." Wen et al. (2017) reported that curcumin inhibits the replication of SARS-CoV-2 by exhibiting its protease inhibitory activity. Curcumin functions as an active antiviral agent in diseases like chikingunya, HIV, hepatitis $\mathrm{C}$ by foiling the access of the virus particle into the host cell. This in turn reduces viral replication. Also, curcumin is able to modulate the activity of certain molecular events as well in the virus lifecycle, which includes gene expression inhibition as observed in herpes virus and HPV (Joe et al., 2004).

Curcumin's ability to target different virus replication pathways, thus impeding viral growth and multiplication makes it a model candidate for an antiviral drug. Based on their molecular docking study, Utomo et al. (2020), reported that curcumin binds and inhibits SARS-CoV-2 protease, spike glycoprotein RBD, and PDACE2 receptors which are essentially involved in virus infection. According to Liu et al. (2017) curcumin has an antagonistic effect on the pro-inflammatory action of angiotensin II-AT1R, thus causing a decline in the level of proinflammatory cytokines and free radicals. In silico research conducted by Khaerunnisa et al. (2020), elucidated that demethoxy curcumin and curcumin may inhibit COVID-19 main protease (Mpro). The proteolytic activity of Mpro plays a significant role in the activation of helicase and RNA-dependent RNA polymerase (Rut et al., 2020). Compounds eliciting an Mpro inhibitory effect are potential agents for COVID-19 treatment (Zhang et al., 2020).

Jena et al. (2021) used Auto dock Vina 1.1.2. to study the binding modes of curcumin with coronavirus spike (S) protein and ACE2. The binding energy and affinity were documented to be $-7.9 \mathrm{kcal} /$ $\mathrm{mol}$ and $-7.8 \mathrm{kcal} / \mathrm{mol}$, respectively. The values are suggestive of the fact that curcumin exhibits a strong binding affinity with Sprotein as well as ACE2. According to the in silico study by Maurya et al. (2020), curcumin demonstrated a high-affinity for the S glycoprotein by forming six hydrogen bonds (Maurya et al., 2020). Moreover, docking results have demonstrated that by forming two hydrogen bonds, curcumin interacted with the proteins active site (Maurya et al., 2020). The entry of SARS-CoV-2 through the S protein is facilitated by the transmembrane protein serine protease 2 (TMPRSS2) (Hoffmann et al., 2020). In silico analyses focusing on TMPRSS2 showed that curcumin forms four hydrophobic interactions and an H-bond with TMPRSS2 (Motohashi et al., 2020). The results of studies on curcumin as prospective remedy for COVID-19 are encouraging. Curcumin can be effectively administered as part of a combinatorial therapy (Rattis et al., 2021)

\subsection{Piper nigrum (Black Pepper)}

The king of spices or pepper is a member of family Piperaceae. It finds extensive use as a medicine, in perfumery and preservative. The major alkaloid in pepper is piperine (1-peperoyl piperidine), which has been in use as a medicine not only by Indian allied sciences as Ayurveda, Unani and Siddha but also by Chinese and Tibetans. The utility of piperine extends from its use as an antimicrobial, antiasthmatic, antidepressant, analgesic, antihypertensive, anti-inflammatory, antioxidant, antipyretic as well as antitumor (Damanhouri and Ahmad, 2014; Yoo et al., 2019; Jafri et al., 2019; Tiwari et al., 2020).

The binding between piperine and 3CL-protease of COVID-19 is very strong, in fact even better than hydroxychloroquine and 
chloroquinein. This binding promotes protein folding, thus causing structural changes in the main 3CL-protease of SARS-CoV-2 (Lenin et al., 2020).

In silico studies by Rajagopal et al. (2020) suggest that piperine can be used against COVID-19 as it works in a manner similar to hydroxychloroquine. They suggested that not only piperine but piperdardiine and piperanine, too possess remedial possibilities. Piperine has been found, via in silico studies to inhibit not only the spike proteins in SARS-CoV-2, but is effective against mutated forms (S, 12 mutations) of the spike protein and was found to dislocate complex with ACE2 receptor ( Nag et al., 2021). Shekh et al. (2020) recorded that piperine associates with the amino acids 166-Gly and 177-Gly of SARS-CoV-2 RBD Spro motifs and is stabilized by weak interactions as hydrogen bonds and van der Waals interactions with good binding scores. Piperine, was found to have a docking score prediction $-6.8 \mathrm{kcal} / \mathrm{mol}$ and it leads to H-bonds with $\mathrm{Thr} 25$, Ser144 and Cys145 residues Mpro. Roat et al. (2020), in a MD simulation study observed stable interactions between piperine and both proteases RBD Spro and Mpro of SARS-Cov-2 based on PCA and binding free energy results. This binding facilitates the inhibition of replication as well as translation of viral proteins, effectively due to specific hindrances caused due to mutarotation. Thus, piperine evolves as a lead molecule for the treatment of SARS-CoV-2,

\subsection{Syzygium aromaticum (Clove)}

Clove is an evergreen tree from Myrtaceae family, growing in tropical climates. For over 2000 years, its use has been widespread across the globe in traditional medicine as well as for culinary purposes. The dried clove buds are largely used and eugenol is the primary essential oil (70-90\%). Other important phytochemicals include $\beta$-caryophyllene, eugenyl acetate, and several sesquiterpenes (Zheng et al., 1992; Chaieb et al., 2007). It is endowed with medicinal properties and is used as an anti-inflammatory, immunostimulatory, antithrombotic as well as antibacterial, suggesting it as an important candidate in fight against the COVID-19 disease, especially for patients with comorbidities to prevent secondary infections (Bahramsoltani and Rahimi, 2020) .

Eugenol has shown to possess antiviral properties and is effective against HSV-1 and HSV-2, respectively (Benencia and Courrèges 2000). Its anti-inflammatory properties help protect the lungs as it recovers lipopolysaccharide-induced injury. It also inhibits leukocytes recruitment and downregulates the IL-6 and TNFexpression (Barboza et al., 2018).

Eugenol, is reported to associate with spike S1, and thus prevents its interaction with ACE2, thereby inhibiting the entry of SARSCoV-2 into host cells. It affects the immune system as it reduces the virus induced activation of NF- $\mathrm{\kappa B}$ as well as the cytokine storm as it downregulated expression of IL-6, IL-1 $\beta$ and TNF $\alpha$. Further, this facilitates lowering the inflammation in lungs, fever and improves cardiac function (Paidi et al., 2021).

Silva et al. (2020), studied the efficacy of aromatic oils including eugenol, carvacrol and menthol, using molecular docking techniques against SARC-CoV-2. The docking scores inferred that eugenol has an affinity towards the main protease (Mpro) on the spike.

\subsection{Tinospora cordifolia (Giloy)}

Tinospora cordifolia (Giloy) belongs to the Menispermaceae family and is indigenous to Asian counties like Myanmar, India, Sri Lanka and China. In India, this plant is commonly referred to as Guduchi and has extensive applications in Ayurvedic medicine (Singh et al., 2020). Giloy is employed as a treatment modality against various inflammatory and allergic condions (Kumar, 2020). According to the study conducted by Pruthvish and Gopinatha (2018), the crude stem extract of giloy exhibited antiviral properties against herpes simplex virus.

The key COVID-19 protease Mpro or 3CLpro is an important target of antiviral approaches as it plays a key role in the virus infectious process. According to the molecular docking study of Shree et al. (2020), one of the phytoconstituents, tinocordiside, has been found to inhibit the Mpro of SARS-COVID-19. It revealed highest binding affinity compared to built-in ligand N3 for SARS-CoV-2 Mpro as per YASARA scoring and binding energy of $8.10 \mathrm{kcal} / \mathrm{mol}$. Also, different compounds isolated from giloy like magnoflorine, berberine and isocolumbin presented high binding efficacy against the major surface proteins of SARS-CoV-2. This indicates that giloy has the potential to interfere with virus replication and infection (Sagar and Kumar, 2020).

The in silico study conducted by Chowdhury (2020) using tools of molecular docking and molecular dynamics have suggested that of all the phytoconstituents present in Tinospora cordifolia, berberine can effectively inhibit 3CLpro. However, according to the docking study of Krupanidhi et al. (2020), it was suggested that tinosponone is a potent inhibitor of the 3CL main protease of SARS-CoV-2 and was shown to exhibit a binding affinity of $-7.7 \mathrm{kcal} / \mathrm{mol}$. Among 28 active phytochemicals from $T$. cordifolia (giloy), only one compound, namely; tinocordiside (CID_177384) showed highest binding affinity as compared to built-in ligand N3 for SARS-CoV-2 Mpro as per YASARA scoring. Tinocordiside has binding energy of $8.10 \mathrm{kcal} / \mathrm{mol}$. According to the results of docking analysis and ADMET studies conducted by Jena et al. (2021) a total five phytoconstituents of T.cordiofolia are promising therapeutic agents for COVID-19. These include alkaloids, steroids, terepenoids, octacosanol and heptacosanol.

\subsection{Zingiber officinale (Ginger)}

Ginger (Zingiber officinale) is a key medicinal plant. It is rich in many phytochemicals having therapeutic properties, prominent being steroids, phenols and alkaloids (Singh et al., 2021). It is reported that these compounds of ginger exhibit anti-inflammatory, antipyretic, analgesic, antiemetic and antiarthritic properties. Researchers have also found ginger to be an effective therapy in many viral infections as Chikungunya, Herpes simplex, SARS-CoV2 and Influenza to name a few (Admas, 2020; Sulochana et al., 2020). In a molecular docking study conducted by Ahkam et al. (2020), ginger bioactive compounds were found to inhibit antiSARS-CoV-2 activity by interacting with the main spike protein, S. This impeded virus binding with angiotensin-converting enzyme 2 (ACE2) receptor. The $\mathrm{S}$ protein plays a crucial role in the entry of SARS-CoV-2 during infection as it binds with hosts ACE2 receptor leading to a fitting environment for the virus to replicate (Walls et al., 2020). The main protease (MPro) is responsible for processing the poly-proteins, viz., pp1a and pplab during the replication 
phase of the virus (Hilgen Feld, 2014). According to the study conducted by Haridas et al. (2021), the in silico target binding behaviour of the major phytochemical components of ginger suggested that it may have neutralising effect on SARS-CoV-2 by inhibiting the spike glycoprotein in the virus and the enzyme ACE2 in the host, both being critical for virus entry into the host cell.

Also, the activity of PLpro (SARS-CoV-2-related papainlike protease) cleaves polyprotein $\mathrm{a} / \mathrm{b}(\mathrm{PP} \mathrm{a} / \mathrm{b})$, and thus is an important requirement for SARS-COVID-19 replication and survival (Dibakar et al., 2020). This makes PL pro a noteworthy target of anti-SARS-CoV-2 pharmacological approach (Al Ajmi et al., 2020). Molecular docking studies suggested that 6-gingerol reveals high binding affinity for different viral proteins that are vital for viral replication and survival like the $\mathrm{S}$ protein and several RNA binding proteins. Docking studies have also revealed that ginger and its derivatives like gingerol and zingiberenol, to name a few, interact with key residues in the catalytic domain of Mpro. Joshi et al. (2020) conducted a computational study which suggested that sesquiphellandrene, a ginger-derived terpene binds to $\mathrm{S}$ protein, thus impeding the $\mathrm{S}$ protein-ACE2 interaction (Joshi et al., 2020; Jafarzadehab et al., 2021). According to the study of Wijaya et al. (2021), 4-gingerol was elucidated to have the lowest binding energy against SARS-CoV-2 Mpro, and is thus proven to be a potent inhibitor of SARS-CoV-2.

\subsection{Capsaicin}

Capsaicin, chemically known as trans-8-methyl-N-vanillyl-6nonenamide is the main component in varieties of spices like red chilli, hot peppers, etc. (Ann Bode et al., 2011). It possesses natural antioxidant and pharmacological properties (Pandey and Rizvi, 2009; Pathak et al., 2014; Rosa et al., 2002). Capsaicin is a general trigger to cough as it activates of TRPV1 (Khalid et al., 2014) although antagonists of TRPV1 are not effective. According to TernestenHasseus et al. (2014), when capsaicin was administered orally for one month, showed improvement in cough through putative desensitization mechanism. As per the directives of U.S. FDA, it has been in use as a principal component for various pharma formulations as a line of treatment of several human diseases (Kraft et al., 2013). Bourne et al. (1999) and Steiner et al. (2007) reported antiviral properties of capsaicin which helped in reduction of recurrent HSV infection and Varicella zoster infection.

As per Moldock molecular docking, algorithm capsaicin has binding potential with ASP 153 and lysin 102 with docking energy of - 54 $\mathrm{kcal} / \mathrm{mol}$. According to Anish Nag et al. (2021), capsaicin was found to have binding potential with mutated $\mathrm{S}$ proteins with binding energy as $-7.867 \mathrm{kcal} / \mathrm{mol}$ and also with S-hACE2 (Angiotensinconverting enzyme 2) protein complex with docking energy as -9.385 kcal/mol (Lenin Gonzalez-Paz et al., 2020 ). It has been reported that capsaicin has a potential of binding strongly to $3 \mathrm{CL}$ protease enzyme of coronavirus as compared to antimalarial drugs. This promotes structural changes in viral protease enzyme that includes folding enzyme as well (Lenin Gonzalez-Paz et al., 2020). Another study on molecular docking have reported docking energy of capsaicin with COVID-19 MPro and RNA dependent RNA polymerase (RdRp) as -6.2 and $-7.3 \mathrm{kcal} / \mathrm{mol}$, respectively (Brahmaiah Pendyala et al., 2020).

\subsection{Catechin}

Natural polyphenols present in plants are well-documented as therapeutic and modulatory agents. They are also known to exhibit antiviral properties. Catechins exhibit antiviral activity against a wide range of human viruses including influenza, hepatitis B, hepatitis C, herpes simplex virus and HIV (Call and et al., 2012; Ide et al., 2016). Ganeshpurkar and Saluja (2017) studied the immunomodulatory targets of catechins by analysing in silico interactions. The docking scores revealed the ability of catechin to interact with TNF $\alpha$, IL1 $\beta$ to name a few. Ghosh and coworkers (2020), reported that gallocatechin-3-gallate, a compound derived from Camellia sinensis (Green tea), showed significantly more activity $(-9.0 \mathrm{kcal} / \mathrm{mol})$ to the COVID-19 Mpro amino acids of E166, F140, H163, S144, C145, G113 (H-bond) and M49, L141, M165, E166, R188 (Hydrophobic interactions). Many phytoactive components present in C. sinensis act as effective SARS CoV-2 Mpro inhibitors (Bhardwaj et al., 2020).

According to molecular docking study of Ghosh et al. (2020), the three catechins found in tea, viz., EGCG, ECG and GCG interact with the residues of MPro. The affinity with which these three polyphenols bind, ranges between -7.6 and $-9.0 \mathrm{kcal} / \mathrm{mol}$ with the lowest affinity for GCG and the highest affinity for EGCG. Binding free energy estimations using the MM-GBSA method also reveals that Mpro-GCG complex $(-53.54 \mathrm{kcal} / \mathrm{mol})$ is relatively more stable than Mpro-ECG $(-48.92 \mathrm{kcal} / \mathrm{mol})$ and Mpro-EGCG complex $(-43.56$ $\mathrm{kcal} / \mathrm{mol}$ ). These findings strongly support that catechins can be a promising anti-COVID-19 drug candidates.

Epigallocatechin gallate demonstrated the lowest binding energy with the COVID-19 spike protein $(-130.566 \mathrm{kcal} / \mathrm{mol})$. Low binding energy values indicate high protein-ligand binding affinity. The affinity value for EGCG, obtained from Auto DockVina, was observed to be $-9.2 \mathrm{kcal} / \mathrm{mol}$ (Subbaiyan et al., 2020).

Hewan et al. (2020) demonstrated catechins to be chiral compounds. To study the same, they employed the MOE software. The catechins were resolved and identified according to their chirality.

\subsection{Kaempferol}

Kaempferol (3,5,7-trihydroxy-2-(4-hydroxyphenyl)-4H-1benzopyran-4-one) is a flavonoid present in several plants which are edible, e.g., broccoli, kale, tea, beans, tomato, grapes, etc. It is also found and used as medicine, e.g., Tilia spp, Moringa spp. Moringa oleifera, etc., (Calderon-Montano et al., 2011). Chemically, kaempferol is tetrahydroxy flavone (Li et al., 2015). Numerous studies have proven kaempferol as anticancer, antimicrobial, antioxidant, and antiviral in action (Devi et al., 2015). It also possesses antidiabetic, cardioprotective, analgesic, neuroprotective, anti-osteoporotic, and antiallergic activities (Lei et al., 2019; Sharma et al., 2007). Based on the research by Jeong et al. (2009), kaempferol is shown to inhibit H1N1 along with H9N2. In vitro analysis showed the inhibitory activity of it against hepatitis B virus (Li et al., 2008). Kaempferol was found to inhibit viral replication leading to act as antiviral agent against Japanese encephalitis virus (Zhang et al., 2012).

Auto Dock Vina docking was carried out between kaempferol and main protease (3CLpro) which revealed 10 different conformations 
of kaempferol found to be antiviral (Trott and Olson, 2010). These docking predictions significantly approve that kaempferol is potent agent to interact with 3CLpro. Molecular docking analysis in 2021 by Laleh Babaeekhou et al. (2021), indicated a high affinity of kaempferol 3-O-rutinoside, querciturone and neodiosmin against CoV-2-SP with docking score values of $-10.575,-9.904$ and -10.208 $\mathrm{kcal} / \mathrm{mol}$ with ki values of $0.016606,0.051749$ and 0.030921 , respectively. Additionally, the total binding energy for $1^{\text {st }}$ conformation calculated by MM GBSA module was found out to be $-25.67 \mathrm{kcal} / \mathrm{mol}$, whereas for second and third it was $-17.21 \mathrm{kcal} /$ $\mathrm{mol}$ and $-26.81 \mathrm{kcal} / \mathrm{mol}$, respectively (Genheden and Ryde, 2015). Cytopathic effect (CPE) inhibition assay was performed on Vero E6 cells to investigate inhibitory activity of kaempferol (Ma et al., 2020; Sebaugh, 2011). As per the report, SARS-CoV-2 causes cell detachment, rounding and death in infected Vero E6 cells. On incubation of these cells with kaempferol at concentration (62.50$125.00 \mu \mathrm{g} / \mathrm{ml}$ ) showed significant decrease in CPE of Vero E6 cells. These discoveries have proven the promising antiviral effect of kaempferol against SARS-CoV-2.

\subsection{Quercetin}

Among numerous natural products, a dietary flavonoid quercetin is recognized to possess potential to treat chronic diseases and ageing processes in human beings. It is also known to hold antiviral properties (Pawan et al., 2020; Zeng et al., 2020). Quercetin is mostly found in vegetables and fruits including capers, broccoli, onions, grapes, onions, berries, tea, wine along with nuts, barks, leaves, flowers and spices (Russo et al., 2010; Terahara et al., 2015; Kyle et al., 2006). It is found to inhibit production of NLRP3 inflammasome mediated IL-1 $\beta$ (Tőzsér et al., 2016). Lee et al. (2017) confirmed a dose-dependent antiviral activity of quercetin against HSV-1 and HSV-2, in cell cultures. It is also reported by Debiaggi et al. (1990) that quercetin can inhibit viruses of respiratory origin in cell culture. Quercetin inhibits the cytopathic effects triggered by rhinovirus, type 7, 11, 12, 19 echovirus and A21, B1 coxsackievirus along with type 1 Sabin poliovirus (Ishitsuka, 1992.) In 2018 , it was demonstrated by González-Búrquez et al. (2018) that quercetin shows antiviral activity by decreasing viral expression and improving cellular viability. Supplementation of quercetin can encourage antioxidant activity (Xu et al., 2019), immunoprotective, anti-inflammatory activities (Saeedi-Boroujeni and MahmoudianSani, 2021), along with antidiabetic and anticarcinogenic potential (Rauf et al., 2018; Carullo et al., 2017; Carrasco-Pozo et al., 2016). Also, it exhibits ability to prevent peroxidation of lipid, aggregation of platelets and permeability of capillary.

In silico as well as in vitro studies by Agrawal et al. (2020), demonstrated that quercetin can restrict several stages of replication cycle of the coronavirus like 3CLpro, NTPase/helicase and PL pro subsequently preventing its entry into host. Liu et al. (2016) through an in silico study explained that quercetin can be a potent inhibitor of influenza A H7N9 and H1N1. Docking analysis by Auto Dock 4.2 demonstrated quercetin as inhibitor of NS2 protease in HCV with binding energy of $-7.95 \mathrm{kcal} / \mathrm{mol}$. (Sajitha et al., 2015). Molecular docking examination also proved that it may cause interaction with replication machinery like NS5B polymerase, HCV NS3 helicase and p7 proteins (Fatima et al., 2014; Mathew et al., 2015). In vitro studies by Yi et al. (2004), also demonstrated that quercetin has a potential to block entry of SARS-coronavirus into Vero E6 cells with a $\mathrm{EC}_{50}$ of $83.4 \mu \mathrm{M}$ along with low cytotoxicity $\left(\mathrm{CC}_{50} 3.32 \mathrm{mM}\right)$. Docking studies of quercetin to 3CLpro, recommended that it can bind to each target firmly with energy of binding $-5.6 \mathrm{kcal} / \mathrm{mol}$ to 3CLpro (Smith et al., 2020). They identified quercetin as one of the 5 top most potent compounds amongst the drugs, natural products and metabolites having binding capacity to the interface site and ability to disrupt infection process. This study revealed the interaction between viral spike protein of SARSCoV-2 and ACE2 protein. It is well known that proteases play vital roles in replication of virus, and SARS-CoV-2 specifically has 6LU7 to be the main protease (Mpro). In vitro molecular docking analysis of interaction between quercetin and viral protease demonstrates hydrogen bonding capacity of quercetin with amino acids His164, Glu166, Asp187, Gln192, and Thr190 of 6LU7 at active site (Khaerunnisa et al., 2020). According to the study, the binding energies obtained from docking 6LU7 quercetin is $-8.17 \mathrm{kcal} / \mathrm{mol}$. Molecular docking studies by Auto Dock Vina discovered that quercetin-3-O-rhamnoside shows highest binding affinity with energy of $-9.7 \mathrm{kcal} / \mathrm{mol}$. These analysis also revealed that flavonoids in glycosylated form are potential inhibitors for protease of SARSCoV-2 (Cherrak et al., 2020). Docking studies by Bhowmik et al. (2019) confirmed the potential interaction of quercetin with ASP38 amino acid residue of ACE2 receptor which could help in preventing the attachment of coronavirus to the host cell.

\section{Conclusion}

Therapy against SARS-CoV-2, the causative agent of COVID-19, still continues to evade mankind. Drugs to curb infection have been successful but these are mostly antiviral effective against many other viruses. There still is no drug approved directed against the virus in question. This study is an attempt to evaluate medicinal and aromatic plants and nutraceuticals though in silico studies for their properties to inhibit the attack and replication of the virus (Figure 2). Table 1 compared the various plants studied. Amongst all the phytochemicals reviewed, allicin and piperine appears to be most promising, besides curcumin, quercitin and tinocordiside. In silico studies are suggestive of time-saving drug development as the initial steps are fast-tracked. These perspective candidates have good binding energies and can prove to be potential molecules to develop anti-COVID-19 drugs.

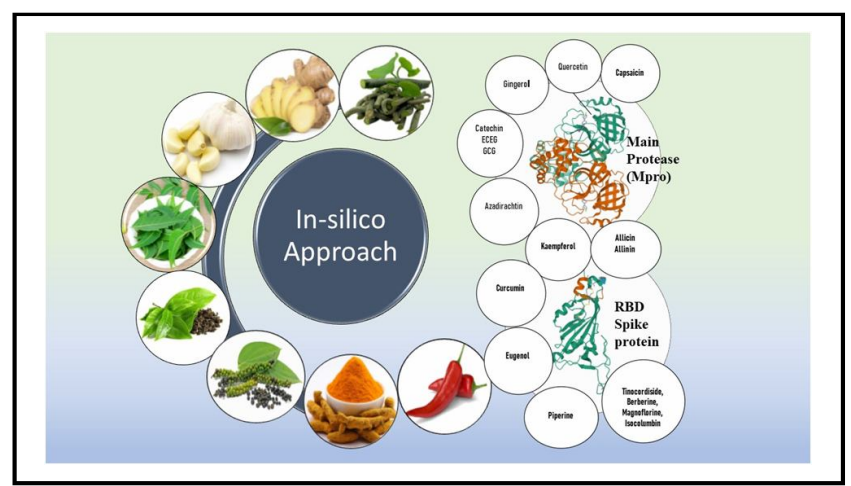

Figure 2: In silico approach to drug development for COVID-19. 
Table 1: Summary of prospective candidates for COVID-19 therapy

\begin{tabular}{|c|c|c|c|c|}
\hline Name of the compound & Active component & Structure & Binding energy in $\mathrm{Kcal} / \mathrm{mol}$ & References \\
\hline Curcuma longa & Curcumin & & S protein: - 7.9ACE2: - 7.8 & Jena et al. (2021) \\
\hline Zingiber officinale & Gingerol & & S Protein: - 38.60ACE2:46.85 & Haridas et al. (2021) \\
\hline Tinospora cordifolia & $\begin{array}{l}\text { Tinocordiside, } \\
\text { Berberine, } \\
\text { Magnoflorine, } \\
\text { Isocolumbin }\end{array}$ & & $\begin{array}{l}\text { 3CL MPro: }-7.7 \mathrm{~N} 3 \text { MPro: } \\
-8.10\end{array}$ & $\begin{array}{l}\text { Krupanidhi et al. } \\
(2020)\end{array}$ \\
\hline Allium sativum & Allicin ajoene & & MPro: -4.4 to -3.4 . & Mahmoud etal. (2020) \\
\hline Camellia sinesis & $\begin{array}{l}\text { Catechin, EGCGE } \\
\text { CGGCG }\end{array}$ & & $\begin{array}{l}\text { MPro: }-53.54,-48.92,-43.56 \\
\text { S protein: }-130.566\end{array}$ & $\begin{array}{l}\text { Subbaiyan et al. } \\
(2020)\end{array}$ \\
\hline Piper nigrum & Piperine & & RBD sPro: -6.8 & Shekh et al. (2020) \\
\hline Azadirachta indica & Azadirachtin & & $\begin{array}{l}\text { S-RBD-ACE2 }-129 \pm 19 \mathrm{~S}- \\
\text { RBD }-152 \pm 29 \mathrm{~kJ} \text { mol” }\end{array}$ & Daniel et al. (2021) \\
\hline
\end{tabular}




\begin{tabular}{|l|l|l|l|l|}
\hline Quercetin & & & & $\begin{array}{l}\text { Smith, et al. (2020) } \\
\text { Cherrak et al. (2020) }\end{array}$ \\
\hline Kaempferol & & $\begin{array}{l}\text { 3CL Pro: }-5.6 \text { 6LU7: -8.17, } \\
\text { Laleh Babaeekhou } \\
\text { (2021) }\end{array}$ \\
\hline Capsaicin & & protein: -7.867 & & \\
\hline
\end{tabular}

\section{Acknowledgements}

Financial and infrastructural support to the Department of Biochemistry from Shri Vile Parle Kelavani Mandal (SVKM) and Mithibai College (Autonomous) is gratefully acknowledged.

\section{Conflict of interest}

The authors declare no conflicts of interest relevant to this article.

\section{References}

Admas, C. (2020). Ginger fights multiple viral infections. The Journal of Plant Medicines https://plantmedicines.org/ginger-fights-multiple virus-infections.

Akin-Osanaiya, B. C.; Nok, A. J.; Ibrahim, S.; Inuwa, H. M.; Onyike, E.; Amlabu, E. and Haruna, E. (2013). Antimalarial effect of neem leaf and neem stem bark extracts on Plasmodium berghei infected in the pathology and treatment of malaria. Intern. Jour. of Res. in Biochem. Biophy., 3(1):7-14.

Aljindil, T. (2012). The immunomodulatory effect of neem (Azadirachta indica) seed aqueous, ethanolic extracts and Candida albicans cell wall mannoproteins on immune response in mice vaccinated with Brucella Rev-1. Iraqi J. Vet. Med., 36:55.

AlAjmi, A.F.; Azhar, A. and Owais, M. (2020). Antiviral potential of some novel structural analogs of standard drugs repurposed for the treatment of COVID-19. J. Biomol., Struct. Dyn. pp:1-13.

Alzohairy, M. A. (2016). Therapeutics role of Azadirachta indica (Neem) and their active constituents in diseases prevention and treatment. Evid. Based Complement. Alternat. Med., 14(1):31-41.

Anish Nag.; Subhabrata Paul.; Ritesh Banerjee. and Rita Kundu (2021). In silico study of some selective phytochemicals against a hypothetical SARS-CoV-2 spike RBD using molecular docking tools, Comput. Biol. Med.. 137:104-818.

Badam, L.; Joshi, S. P. and Bedekar, S. S. (1999). 'In vitro' antiviral activity of neem (Azadirachta indica. A. Juss) leaf extract against group B coxsackieviruses. Journal of Communicable Diseases, 31(2):79-90.

Bahramsoltani, R. and Rahimi, R. (2020). An evaluation of traditional Persian medicine for the management of SARS-CoV-2. Front. Pharmacol., pp: 11 .
Barboza, J.N.; da Silva Maia, B. F. C.; Silva, R.O.; Medeiros, J.V.R. and de Sousa, D.P. (2018) An overview on the anti-inflammatory potential and antioxidant profile of eugenol. Oxid. Med. Cell Longev., pp:395726.

Basir, S. and Shailey, S. (2012). Strengthening of antioxidant defense by Azadirachta indica in alloxan diabetic rat tissues. Journal of Ayurveda and Integrative Medicine, 3(3):130.

Benarba, B. and Pandiella, A. (2020). Medicinal plants as sources of active molecules against COVID-19. Front. Pharmacol., 11:1189.

Benencia, F. and Courrèges, M.C. (2000). In vitro and in vivo activity of eugenol on human herpesvirus. Phytotherapy Res. PTR., 14:495500 .

Bhowmik, D.; Nandi, R. and Prakash, A. (2021). Evaluation of flavonoids as 2019-nCoV cell entry inhibitor through molecular docking and pharmacological analysis. Heliyon., 7:e06515.

Borkotoky, S. and Banerjee, M., (2020). A computational prediction of SARS$\mathrm{CoV}-2$ structural protein inhibitors from Azadirachta indica (Neem). J. Biomol. Struct. Dyn., pp:1-11.

Bourne, N.; Bernstein, D. and Stanberry, L.R. (1999). Civamide (cis-capsaicin) for treatment of primary or recurrent experimental genital herpes. Reviews, 43(11):2685-268.

Carullo, G.; Cappello, A. R.; Frattaruolo, L.; Badolato, M.; Armentano, B. and Aiello, F. (2017). Quercetin and derivatives: Useful tools in inflammation and pain management. Fut. Med. Chem., 9:79-93.

Casey, R. (2005) Bioinformatics in computer-aided drug design. Beye NET WORK. Accessed 24 May 2013http://www.b-eye-network.com/print/ 852.

Chaieb, K.; Hajlaoui, H.; Zmantar, T.; Kahla-Nakbi, A.B.; Rouabhia, M.; Mahdouani, K. and Bakhrouf, A. (2007). The chemical composition and biological activity of clove essential oil, Eugenia caryophyllata (Syzigium aromaticum L. Myrtaceae): A short review. Phytother. Res., 21:501-506.

Cherrak, S.A.; Merzouk, H. and Mokhtari-Soulimane, N. (2020). Potential bioactive glycosylated flavonoids as SARS-CoV-2 main protease inhibitors: A molecular docking and simulation studies. PLoS ONE, 15:240-653.

Chowdhury Papia (2021). In silico investigation of phytoconstituents from Indian medicinal herb 'Tinospora cordifolia (giloy)' against SARSCoV-2 (COVID-19) by molecular dynamics approach. .J Biomol. Struct. Dyn., 39(17):6792-6809. doi:10.1080/07391102.2020. 1803968. 
Cramer, R.D.; Patterson, D.E. and Bunce, J.D. (1988). Comparative molecular field analysis (CoMFA). 1. Effect of shape on binding of steroids to carrier proteins. J. Am. Chem. Soc., 110:5959-5967.

Damanhouri, Z. A. and Ahmad, A. (2014). A review on therapeutic potential of Piper nigrum L. (black pepper): The king of spices. Med. Arom. Plnt., 3:161.

Daniel, M.; Shadrack, A.; Said,A. H.; VuaiMtabazi, G.; Sahinilogo. and Isaac, Onoka B., (2021). In silico study of the inhibition of SARS-COV-2 viral cell entry by neem tree extracts. RSC Adv., 11:26524-26533.

Debiaggi, M.; Tateo, F.; Pagani, L.; Luini, M. and Romero, E. (1990). Effects of propolis flavonoids on virus infectivity and replication. Microbiologica, 13(3):207-213.

Devi, K.P.; Malar, D.S.; Nabavi, S.F.; Sureda, A.; Xiao, J.; Nabavi, S.M. and Daglia, M. (2015). Kaempferol and inflammation: From chemistry to medicine. Pharmacol. Res., 99:1-10.

Dibakar, G.; Mukesh, K.G.; Sunil, D. and Amit, K., (2020). Natural product compounds in Alpinia officinarum and ginger are potent SARSCoV-2 papain-like protease inhibitors. Chem Rxiv 10.26434/ chemrxiv.12071997.v1.

Du, P.X.; Chou, Y.Y. and Santos, H.M. (2021). Development and application of human coronavirus protein microarray for specificity analysis. Anal. Chem., 93(21):7690-7698.

Dwivedi, V. D.; Bharadwaj, S.; Afroz, S.; Khan, N.; Ansari, M. A. and Yadava, U., (2020). Anti-dengue infectivity evaluation of bioflavonoid from Azadirachta indica by dengue virus serine protease inhibition. J. Biomol. Struct. Dyn., 39(4):1417-1430. doi:10.1080/073911 02.2020 .1734485 .

Ekins, S.; Freundlich, J.S.; Hobrath, J.V.; White, E.L. and Reynolds, R.C. (2014) Combining computational methods for hit to lead optimization in Mycobacterium tuberculosis drug discovery. Pharm. Res., 31(2):414-435.

El-SaberBatiha, G.; Magdy Beshbishy, A.; Wasef, L.G.; Elewa, Y.H.; Al-Sagan, A.A and ElHack, A. (2020). Chemical constituents and pharmacological activities of garlic (Allium sativum L.): A review. Nutrients, 12(3):872.

Fatima, K.; Mathew, S. and Suhail, M. (2014). Docking studies of Pakistani HCV NS3 helicase: A possible antiviral drug target. PLoS One, 9(9):e106339. doi:10.1371/journal.pone.0106339.

Frengki, F.; Deddi, P. P., Fatma, S. W.; Daan, K. H. V. and Vivi, S. (2020). Potential antiviral of catechins and their derivatives to inhibit Sars-Cov-2 receptors of Mpro protein and spike glycoprotein in COVID-19 through the in silico approach. Reviews, pp:440.

Genheden, S. and Ryde, U. (2015). The MM/PBSA and MM/GBSA methods to estimate ligand binding affinities. Exp. Opn. Drug Discov., 10(5): 449-461.

Ghosh, R.; Chakraborty, A.; Biswas, A. and Chowdhuri, S. (2020). Evaluation of green tea polyphenols as novel coronavirus (SARS-CoV-2) main protease (Mpro) inhibitors: An in silico docking and molecular dynamics simulation study. Reviews, pp:4362-4374.

González-Búrquez, M.D.J.; González-Díaz, F.R. and García-Tovar, C.G. (2018) Comparison between in vitro antiviral effect of mexican propolis and three commercial flavonoids against canine distemper virus. Evid. Based Complement. Alternat. Med., 9.doi:10.1155/2018/ 7092416

Gonzalez-Paz, Lenin A., Carla A.; Luis S.; Freddy Romero, J. L.; Paz, Joan.; Aleivi E. Pérez;;Ernesto San-Blas. and Ysaias J. Alvarado (2020). Theoretical molecular docking study of the structural disruption of the viral
3CL-protease of COVID19 induced by binding of capsaicin, piperine and curcumin Part 1. A comparative study with chloroquine and hydrochloroquine two antimalaric drugs. Research Square, pp:301324.

Gowrishankar, S.; Muthumanickam, S.; Kamaladevi, A.; Karthika, C.; Jothi, R.; Boomi, P.; Maniazhagu, D. and Shunmugiah, K.P. (2021). Promising phytochemicals of traditional Indian herbal steam inhalation therapy to combat COVID-19: An in silico study.. Food Chem. Toxicol., 148:111-966.

Green, D.V. and Segall, M. (2014). Chemoinformatics in lead optimization. Chem. Drug. Disc., pp:149-178.

Halder, P.; Pal, U.; Paladhi, P.; Dutta, S.; Paul,P.; Pal, S.; Das, D.; Ganguly, G; Dutta, I.; Mandal, S.; Ray, A. and Ghosh, S. (2021). Evaluation of potency of the selected bioactive molecules from Indian medicinal plants with MPro of SARS-CoV-2 through in silico analysis. J. Ayurveda Integrative Med., pp: 100449.

Jafarzadeh, A.; Jafarzadeh,S. and Maryam, N. (2021). Therapeutic potential of ginger against COVID-19: Is there enough evidence? J. Trad. Chin. Med. Sci., 8(4):267-279.

Hansch, C. (1972). Quantitative relationships between lipophilic character and drug metabolism. Drug Metab. Rev., 1:1-14.

Hansch, C. and Fujita, T. (1964). Rho-sigma-pi analysis. A method for the correlation of biological activity and chemical structure. J. Am. Chem. Soc., 86:1616-1626.

Hansch, C.; Hoekman, D.; Leo, A.; Weininger, D. and Selassie, C.D. (2002). Chembioinformatics: Comparative QSAR at the interface between chemistry and biology. Chem. Rev., 102:783-812.

Haridas, F. (2021). Compounds of Citrus medica and Zingiber officinale for COVID-19 inhibition: In silico evidence for cues from Ayurveda. Fut. J. Pharm. Sci., 7:13.

Hewan, J.K. (2021). Potential antiviral of catechins and their derivatives to inhibit SARS-COV-2 receptors of Mpro protein and spile glycoprotein in COVID-19 through in silico approach. Ind. J. Vet. Sci., 14:59-65.

Hilgenfeld, R. (2014). From SARS to MERS: Crystallographic studies on coronaviral proteases enable antiviral drug design. The FEBS Journal, 281:(18)4085-4096.

Hoffmann, M.; Kleine-Weber, H.; Schroeder, S.; Krüger, N.; Herrler, T. and Erichsen, S. (2020). SARS-CoV-2 cell entry depends on ACE2 and TMPRSS2 and is blocked by a clinically proven protease inhibitor. Cell, 181: 271-280.

Ishitsuka, H.; Ohsawa, C. and Ohiwa, T. (1982). Antipicornavirus flavone Ro 09-0179. Antimicrob. Agents. Chemother., 22(4):611-616.

Jafri, A.; Siddiqui, S.; Rais, J.; Ahmad, M. S.; Kumar, S.; Jafar, T. and Arshad, M. (2019). Induction of apoptosis by piperine in human cervical adenocarcinoma via ROS mediated mitochondrial pathway and caspase-3 activation. EXCLI Journal, 18:154-164.

Jahanshahlu, L. and Rezaei, N. (2020). Monoclonal antibody as a potential anti-COVID-19. Biomed. Pharmacother, 129:110-337.

Jena A. B.; Kanungo, N.; Nayak, V.; Chainy, G.B.N. and Dandapat, J. (2019). Catechin and Curcumin interact with corona (2019- nCoV/SARSCoV2) viral S protein and ACE2 of human cell membrane: Insights from computational study and implication for intervention DOI: 10.21203/rs.3.rs-22057/v1 
Jena, S. and Munusami, P. (2021). Computationally approached inhibition potential of Tinospora cordifolia towards COVID-19 targets. Virus. Dis., 32:65-77.

Jeong, H.J.; Ryu, Y.B.; Park, S.J.; Kim, J.H.; Kwon, H.J. and Kim, J.H.(2009) Neuraminidase inhibitory activities of flavonols isolated from Rhodiola rosea roots and their in vitro anti-influenza viral activities. Bioorgan. Med. Chem., 17(19):6816-6823.

Joe, B.; Vijaykumar, M. and Lokesh, B.R. (2004). Biological properties of curcumin-cellular and molecular mechanisms of action. Crit. Rev. Food Sc. Nutr., 44(2):97-111.

Joshi, G.; Krishnan, S. and Kaushik, V. (2020). Molecular docking and simulation investigation: Effect of beta-sesquiphellandrene with ionic integration on SARS-CoV-2 and SFTS viruses. J. Genet. Eng. Biotechnol. 18(1): 78 .

Khaerunnisa, S.; Kurniawan, H. and Awaluddin, R. (2020). Potential inhibitor of COVID-19 main protease (Mpro) from several medicinal plant compounds by molecular docking study. Preprints, pp:30-226.

Khaerunnisa, S.; Kurniawan, H.; Awaluddin, R.; Suhartati, S. and Soetjipto, S. (2020) Potential inhibitor of COVID-19 main protease (Mpro) from several medicinal plant compounds by molecular docking study. Preprints, pp:1-14.

Khalid, S.; Murdoch, R. and Newlands, A. (2014). Transient receptor potential vanilloid 1 (TRPV1) antagonism in patients with refractory chronic cough: A double-blind randomized controlled trial. J. Allergy Clin. Immunol., 134:56-62.

Khan, A.U.; Baig, M.H. and Wadhwa. G. (2011). Molecular docking analysis of new generation cephalosporins interactions with recently known SHVvariants. Bioinfo., 5(8):331-335.

Khan, M.S.; Baig, M.H.; Ahmad, S.; Siddiqui, S.A. and Srivastava, A.K. (2013) design, synthesis, evaluation and thermodynamics of 1-Substituted pyridylimidazo $[1,5-\mathrm{a}]$ pyridine derivatives as cysteine protease inhibitors. PloS One, 8:e69982.

Kraft, K.H.; Brown, C.H.; Nabhan, G.P.; Luedeling, E.; Luna Ruiz Jde J.; Coppen d'Eeckenbrugge, G.; Hijmans, R.J. and Gepts, P. (2013) Multiple lines of evidence for the origin of domesticated HYPERLINK ", in Mexico. Proceedings of the National Academy of Sciences, 11(17):61656170 .

Krupanidhi, S.K.; Abraham Peele, T.C.; Venkateswarulu, V. S. A.; Md Nazneen, B.; John, D.; Babu, A.; Venkata Narayana, G. and Aishwarya (2021). Screening of phytochemical compounds of Tinospora cordifolia for thei inhibitory activity on SARS-CoV-2: An in silico study. J. Biomol. Struct. Dyn. Sep., 39(15):5799-5803.

Kurogi, Y. and Guner, O.F. (2001). Pharmacophore modeling and three dimensional database searching for drug design using catalyst. Curr. Med. Chem., 8:1035-1055.

Laleh, B.; Ghane, M. and Mahdi, A.M. (2021). In silico targeting SARS-CoV2 spike protein and main protease by biochemical compounds. Biologia, 76:3547-3565.

Lee, S.; Lee, H.H.; Shin, Y.S.; Kang, H. and Cho, H. (2017). The anti-HSV-1 effect of quercetin is dependent on the suppression of TLR-3 in RAW 264.7 cells. Arch. Pharm. Res., 40(5):623-630.

Lei, X.; Guo, J.; Wang, Y.; Cui.J.; Feng, B.; Su, Y.; Zhao, H.; Yang, W. and Hu, Y. (2019). Inhibition of endometrial carcinoma by kaempferol is interceded through apoptosis induction, G2/M phase cell cycle arrest, suppression of cell invasion and upregulation of m-TOR/PI3 K signalling pathway. J. Buon., 4:1555-1561.

Lenin, A.; Gonzalez-Paz. Carla, A.; Lossada, L.S. and Moncayo (2020). Theoretical molecular docking study of the structural disruption of the viral 3CL-protease of COVID-19 Induced by binding of capsaicin, piperine and Curcumin Part 1: A comparative study with chloroquine and hydrochloroquine two antimalaric drugs. ZAMA, pp:21.
Li, H.; Ji, H.S.; Kang, J.H.; Shin, D.H.; Park, H.Y.; Choi, M.S; Lee, C.H.; Lee, I.K.; Yun, B.S. and Jeong, T.S. (2015). Soy leaf extract containing kaempferol glycosides and pheophorbides improves glucose homeostasis by enhancing pancreatic $\alpha$-cell function and suppressing hepatic lipid accumulation in db/db Mice. J. Agric. Food Chem., 32:71-99.

Li, H.; Yang, M.; Li, Z. and Meng, Z. (2017). Curcumin inhibits angiotensin IIinduced inflammation and proliferation of rat vascular smooth muscle cells by elevating PPAR- $\gamma$ activity and reducing oxidative stress. Int. J. Mol. Med., 39:1307-1316.

Li, J.; Huang, H.; Feng, M.; Zhou, W.; Shi, X. and Zhou, P. (2008). In vitro and in vivo antihepatitis $B$ virus activities of a plant extract from Geranium carolinianum L. Antiviral Res., 79(2):114-120.

Lim, L.; Shi, J.; Mu, Y. and Song, J. (2014). Dynamically-driven enhancement of the catalytic machinery of the SARS 3C-like protease by the S284-T285-I286/A mutations on the extra domain. PLoS ONE, 9:e101941.

Lim Xin Yi.; The, Bee Ping. and Tan Terence Yew Chin (2021). Medicinal plants in COVID-19: Potential and limitations. Frontiers in Pharmacology, 12:355.

Liu, Z.; Zhao, J. and Li, W. (2016). Computational screen and experimental validation of anti-influenza effects of quercetin and chlorogenic acid from traditional Chinese medicine. Sci. Rep., 6(1):19095.

Lyu, S. Y.; Rhim, J. Y. and Park, W.B. (2005).Antiherpetic activities of flavonoids against herpes simplex virus type 1 (HSV-1) and type 2 (HSV-2) in vitro. Arch. Pharm. Res., 28(11):1293-1301.

M. Calderon-Montano, J.; Burgos-Moron, E.; Perez-Guerrero, C. and Lopez-Lazaro, M. A. (2011). Review on the dietary flavonoid kaempferol. Mini Rev. in Med. Chem., 11(4):129-141.

Ma, Q.; Pan, W.; Li, R.; Liu, B.; Li, C.; Xie, Y. and Huang, J. (2020). Liu Shen capsule shows antiviral and anti-inflammatory abilities against novel coronavirus SARS-CoV-2 via suppression of NF $\kappa \mathrm{B}$ signaling pathway. Pharm. Res., 158:104-850

Macpherson, L.J.; Geierstanger, B.H.; Viswanath, V.; BandellM, Eid, S.R. and Hwang, S. (2005). The pungency of garlic: Activation of TRPA1 and TRPV1 in response to allicin. Curr. Biol., 15:929-934.

Mahmoud, A.A.; Ibrahim, Alaa, H.M.; Abdelrahman, Taha, A.; Hussien, Esraa, A.A. ;Badr Tarik, A.; Mohamed Hesham, R. El-Seedi, Paul, W.; Pare, Thomas, Efferth, Mohamed-Elamir F. and Hegazy (2020). In silico drug discovery of major metabolites from spices as SARS-CoV-2 main protease inhibitors. Comp. Biol. Med., 126:104-146.

Manoharan, Y.; Haridas, V.; Vasanthakumar, K.; Muthu, S.; Thavoorullah, F. and Shetty, P. (2020). Curcumin: A wonder drug as a preventive measure for COVID-19 management. Ind. J. Clin. Biochem., 35:373-375.

Marti, M.; Renom, M.A. ; Stuart, A.C.; Fiser, A.; Sanchez, R.; Melo, F. and Sali A. (2000). Comparative protein structure modeling of genes and genomes. Annu. Rev. Biophys. Biomol. Struct., 29:291-325.

Mathew, S.; Fatima, K. and Fatmi, M.Q. (2015). Computational docking study of p7 ion channel from HCV genotype 3 and genotype 4 and its interaction with natural compounds. PLoS One, 10(6):e0126510.

Maurya, V. K.; Kumar, S.; Prasad, A. K.; Bhatt, M. L. B. and Saxena, S. K. (2020). structure-based drug designing for potential antiviral activity of selected natural products from ayurveda against SARS-CoV-2 spike glycoprotein and its cellular Receptor. Virus. Dis., 31:179-193.

McCord, J.M.; Hybertson, B.M.; Cota-Gomez, A. and Gao, B. (2020). Nrf2 activator PB125 ${ }^{\circledR}$ as a potential therapeutic agent against COVID19. Bio. Rxiv:2020.2005.2016.099788. https://doi.org/10.1101/ 2020. 05.16.099788 
Merad, M.; Soufi, W.; Ghalem, S.; Boukli, F. and Baig, M.H. (2014). Molecular interaction of acetylcholinesterase with carnosic acid derivatives: A neuroinformatics study. CNS and Neurological Disorders Drug Targets, 13(3):440-446.

Meyer, E.F.; Swanson, S.M. and Williams, J.A. (2000). Molecular modeling and drug design. Pharmacol., Ther., 85:113-121.

Mosa, L. K.; Midiwo, J. O. and Kuete, V. (2017). Curcuma longa. In V. Kuete (Ed.), Therapeutic potential against metabolic, inflammatory, infectious and systemic diseases https://doi.org/10.1016/B978-012-809286-6.00019-4.

Murugan, A.N.; Chitra, J. P. and Jeyakanthan, J. (2020). Computational investigation on Andrographis paniculata phytochemicals to evaluate their potency against SARS-CoV-2 in comparison to known antiviral compounds in drug trials. J. Biomol. Struct. Dyn., 16:112.

Nadia, A.; Rivero-Segura, Juan; and C. Gomez-Verjan (2021). In silico screening of natural products isolated from Mexican herbal medicines against COVID-19. Biomol. 11:216. https://doi.org/10.3390/biom 110 20216.

Nag, A.; Paul, S.; Banerjee, R. and Kundu, R. (2021). In silico study of some selective phytochemicals against a hypothetical SARS-CoV-2 spike RBD using molecular docking tools. Comput. Biol. Med., 137:104818 .

Naik, M. R.; Bhattacharya, A.; Behera, R.; Agrawal, D.; Dehury, S. and Kumar, S. (2014). Study of anti-inflammatory effect of neem seed oil (Azadirachta indica) on infected albino rats. J. Health Res. Rev., 1(3): 66 .

Oladele, J.O.; Ajayi, E.I.; Oyeleke, O.M., Oladele, O.T.; Olowookere, B.D.; Adeniyi, B.M.; Oyewole, O.I. and Oladiji, A.T. (2020). A systematic review on COVID-19 pandemic with special emphasis on curative potentials of Nigeria based medicinal plants. Heliyon., 6:1-17.

Ou-Yang, S.S.; Lu, J.Y.; Kong, X.Q.; Liang, Z.-J.; Luo, C. and Jiang, H. (2012). Computational drug discovery. Acta Pharmacol. Sin., 33:1131-1140.

Paidi, R.K.; Jana, M. and Raha, S. (2021). Eugenol, a component of holy basil (Tulsi) and common spice clove, inhibits the interaction between SARS-CoV-2 spike S1 and ACE2 to induce therapeutic responses. J. Neuroimmune. Pharmacol., https://doi.org/10.1007/s11481-02110028-1.

Pandey,P.; Khan, F.; Kumar,A.; Srivastava, A.; Jha and N. Kumar(2021). Screening of potent inhibitors against 2019 novel coronavirus (COVID-19) from Allium sativum and Allium cepa: An in silico approach. Bio. Res. App. Chem., 11(1):7981-7993.

Park, D.S.; Kim, J.M.; Lee, Y.B. and Ahn, C.H. (2008). QSID Tool: A new threedimensional QSAR environmental tool. Journal of Computer-Aided Drug Design, 22(12):873-883.

Pawan, K.; Agrawal,C. and Gerald, B.(2020). Quercetin: Antiviral significance and possible COVID-19 integrative considerations. Natr. Pro. Commun., 15(12):1-10.

Pendyala, Brahmaiah and Patras, A.(2020). In silico screening of food bioactive compounds to predict potential inhibitors of COVID-19 main protease (Mpro) and RNA-dependent RNA polymerase (RdRp). Chem., Rxiv., 10(1):213.

Perdo, H.L. (2010). A systematic review on CADD: Docking and scoring JMPI, pp:47-51.

Pruthvish, R. and Gopinatha, S. M. (2018). Antiviral prospective of Tinospora cordifolia on HSV-1. Int. J.Cur. Micro. App. Sci., 7(01):3617-3624. https://doi.org/10.20546/ijcmas. 2018.701.425.
Rajagopal, K.; Byran, G.; Jupudi, S. and Vadivelan, R. (2020). Activity of phytochemical constituents of black pepper, ginger, and garlic against coronavirus (COVID-19): An in silico approach. Int. J. Health Allied Sci., 9:43-50.

Rathinavel, T.;Palanisamy, M.; Palanisamy, S. and Subramanian, A. (2020). Phytochemical 6-gingerol: A promising drug of choice for COVID19. Intern. J. Adv. Sci., Eng., 6(6):1482-1489.

Rattis, B.A.C.; Ramos, S.G and Celes, M.R.N (2021) Curcumin as a potential treatment for COVID-19. Front. Pharmacol., 12:675287. doi: $10.3389 /$ fphar.2021.675287.

Rout, J.; Bikash, C.S. and Tripathy, U. (2021). In silico investigation of spice molecules as potent inhibitor of SARS-CoV-2. J. Bio. St. Dyn., https://doi.org/10.1080/07391102.2020.1819879.

Russo, M.; Spagnuolo, C.; Tedesco, I. and Russo, G.L. (2010). Phytochemicals in cancer prevention and therapy: Truth or dare? Toxins, 2(4):517551.doi:10.3390/toxins2040517.

Rut, W.; Groborz, K.; Zhang, L.; Sun, X.; Zmudzinski, M. and Pawlik, B. (2020). SARS-CoV-2 Mpro inhibitors and activity-based probes for patientsample imaging. Nat. Chem. Biol., 17:222-228. doi:10.1038/ s41589-020-00689-z.

Saeedi-Boroujeni, A. and Mahmoudian-Sani, M. R. (2021). Anti-inflammatory potential of quercetin in COVID-19 treatment. J. Inflamm. (United Kingdom), 18:1-9.

Sagar, V. K. and Kumar, A. H. S. (2020). Efficacy of natural compounds from Tinospora cordifolia against SARS-CoV-2 protease, surface glycoprotein and RNA polymerase. Preprint, https://doi.org/ 10.21203/rs.3.rs27375/v1.

Sajitha, L.; Thabitha, S.; A., Vino, A.; S., Mohana Priya, A. and Rout, M. (2016). Naringenin and quercetin: Potential anti-HCV agents for NS2 protease targets. Nat. Pro. Res., 30:464-468. https://doi.org/ 10.1080/14786419.2015.10204.

Sankar, M.; Ramachandran, B.; Pandi, B.; Mutharasappan, N.; Ramasamy, V.; Prabu, P.G.; Shanmugaraj, G.; Wang, Y.; Muniyandai, B.; Rathinasamy, S.; Chandrasekaran, B.; Bayan, M.F.; Jeyaraman, J.; Halliah, G.P. Ebenezer and S.K (2021). In silico screening of natural phytocompounds towards identification of potential lead compounds to treat COVID-19. Front. Mol. Biosci., 8:637122. doi: 10.3389/fmolb.2021.637122.

Schwarz, S.; Sauter, D.; Lu, W.; Wang, K.; Sun, B.; Efferth, T. and Schwarz, W. (2012). Coronaviral ion channels as target for Chinese herbal medicine. For. Immunopathol. Dis. Ther., 3:1-13.

Sebaugh, J. (2011). Guidelines for accurate EC50/IC50 estimation. Pharmaceutical Statistics, 10(2):128-134.

Shan, Y.; Kim, E.T.; Eastwood, M.P.; Dror, R.O.; Seeliger, M.A. and Shaw, D.E. (2011). How does a drug molecule find its target binding site? J. Amer. Chem. Soc., 133(24):9181-9183.

Sharma, V.; Joseph, C.; Ghosh, S.; Agarwal, A.; Mishra, M.K. and Sen, E. (2007). Kaempferol induces apoptosis in glioblastoma cells through oxidative stress. Mol. Cancer Ther., 6:2544-2553.

Shekh, S.; Reddy, K.K.A. and Gowd, K.H. (2020). In silico allicin induced Sthioallylation of SARS-CoV-2 main protease. J. Sulphur Chem., pp: $1-12$.

Sher, R.; Abaid, T.; Zahid, M. and Butt, A. K. (2018). Evidence of effectiveness of Azadirachta indica leaves in chronic hepatitis $\mathrm{C}$ in addition of conventional therapy failure. Ann. King Edward Medical University, 24(4).

Shrivastava, D. K. and Swarnkar, K. (2014). Antifungal activity of leaf extract of neem (Azadirachta indica Linn). Intern. Journ. of Current Microbio. and Applied Sci., 3(5):305-308. 
Silva, J.; Figueiredo, P.; Byler, K. and Setzer, W. (2020). Essential oils as antivira agents. Potential of essential oils to treat SARS-CoV-2 infection: An in silico investigation. Int. J. Mol. Sci., 21:3426.

Singh, N.A.; Kumar, P. and Jyoti Kumar, N. (2021). Spices and herbs: Potential antiviral preventives and immunity boosters during COVID-19. Phytotherapy Research, pp:1-13.

Smith $\mathbf{C}$ (2003). Drug target validation: Hitting the target. Nature, $\mathbf{4 2 2}$ 341-345.

Smith, M. and Smith, J.C. (2020). Repurposing therapeutics for COVID-19: Supercomputer-based docking to the SARS-CoV-2 viral spike protein and viral spike protein-human ACE2 interface. Chem. Rxiv., pp:10.

Soloman A.K. (2008). Molecular modelling and drug design.2nd edition (Chennai), MB Publisher, 2008.

Steiner, I.; Kennedy, P.G and Pachner, A.R. (2007). The neurotropic herpe viruses: Herpes simplex and varicella-zoster. Lancet Neurol., 6(1): 1015-1028.

Subbaiyan, S. (2020). In silico molecular docking analysis targeting SARSCoV-2 spike protein and selected herbal constituents. J. Pure Appl. Microbiol., 14(Suppl 1):989-998.

Sulochana, K.; Jangra, G.; Kundu, V.; Yadav, J. P. and Kaushik, S. (2020). Antiviral activity of Zingiber officinale (ginger) ingredients against the Chikungunya virus. Virus Disease, 31:270-276.

Swaan P.W. and Ekins S. (2005). Reengineering the pharmaceutical industry by crash-testing molecules. Drug Disc. Today, 10:1191-1200.

Taft, C.A.; Silva, V.B da.; Silva and C.H.T. de P da. (2008). Current topics in computer-aided drug design. J. Pharm. Sci., 97(3):1089-1098.

Terahara, N. (2015). Flavonoids in foods: A review. Nat. Prod. Commun., 10(3):521-528

Ternesten-Hasseus, E.; Johansson, E.L. and Millqvist, E. (2015). Cough reduction using capsaicin. Respir. Med., 109:27-37.

Thuy, B.T.P.; My, T.T.A.; Hai, N.T.T.; Hieu, L.T.; Hoa, T.T.; Thi Phuong Loan, H.; Triet, N.T.; Van Anh, T.T.; Quy, P.T. and Van Tat, P. (2020). Investigation into SARS-CoV-2 resistance of compounds in garlic essential oil. ACS Omega, 5:8312-8320.

Tiwari, A.; Mahadik, K. R. and Gabhe, S. Y. (2020). Piperine: A comprehensive review of methods of isolation, purification, and biological properties. Medicine in Drug Discovery, 7:100-227

Tiwari, V.; Darmani, N. A.; Yue, B. Y. and Shukla, D. (2010). In vitro antiviral activity of neem (Azardirachta indica L.) bark extract against herpes simplex virus type-1 infection. Phytotherapy Research, 24(8):1132-1140.

Tõzsér, J. and Benkõ, S. (2016). Natural compounds as regulators of NLRP3 inflammasome-mediated IL- $1 \alpha$ production. Mediators Inflamm., 1(1): 1-16.

Trott, O. and Olson, A.J. (2010). AutoDock Vina: Improving the speed and accuracy of docking with a new scoring function, efficient optimization, and multithreading. Journal of Computational Chemistry, 31(2):455-461.

Tuckerman, M.E. and Martyna, G.J. (2000). Understanding modern molecular dynamics: Techniques and Applications. J. Phys. Chem. B., 104: 159-178.
Twomey, J.D.; Luo, S.; Dean, A.Q.; Bozza, W.P.; Nalli, A. and Zhang, B. (2020). COVID-19 update: The race to therapeutic development. Drug Resist. Updates, 53:100-733.

United States Department of Agriculture. (2013). National Nutrient Database for Standard Reference Release 26 Full Report (All Nutrients). Nutrient data for Spices. Ginger

Vardhan, S. and Sahoo, S.K. (2020). In silico ADMET and molecular docking study on searching potential inhibitors from limonoids and triterpenoids for COVID-19. Comput. Biol. Med., 124:103-936.

Venugopalan, S. S. K.; Viswesharan, N. and Aiyalu, R. N., (2011). Neem leaf glucosamine stimulates Interleukin-2 (IL-2) in swiss albino mice. Nat. Preced., 59:231.

Wadood, A.; Ahmed, N.; Shah, L.; Ahmad, A.; Hassan, H. and Shams, S. (2020). In silico drug design: An approach which revolutionarised the drug discovery process. OA Drug Design and Delivery, 1(1):3.

Walls, A. C.; Park, Y.-J.; Tortorici, M. A.; Wall, A.; McGuire, A. T. and Veesler, D. (2020). Structure, function, and antigenicity of the SARSCoV-2 spike glycoprotein. Cell, 181(2):281-292.

Wen, C.C.; Kuo, Y.H.; Jan, J.T.; Liang, P.H.; Wang, S.Y.; Liu, H.G. and Yang, N.S. (2007). Specific plant terpenoids and lignoids possess potent antiviral activities against severe acute respiratory syndrome coronavirus. Journal of Medicinal Chemistry, 50(17):4087-4095.

Wijaya, R. M.; Hafidzhah, M.A.; Kharisma,V. D.; Ansori, A. N. M. and Parikesit,A. A. (2021). COVID-19 in silico drug with zingiber officinale natural product compound library targeting the mpro protein. Makara Journal of Science, 25(3):162-171.

Wojdylo, A.; Oszmianski, J. and Czemerys R. ( 2007). Antioxidant activity and phenolic compounds in 32 selected herbs. Food Chem., 105:9409.

Xu, D.; Hu, M. J.; Wang, Y. Q. and Cui, Y. L. (2019). Antioxidant activities of quercetin and its complexes for medicinal application. Molecules, 24(6): 1123 .

Yang, Y.; Zhu, Z and Wang, X. (2021). Ligand-based approach for predicting drug targets and for virtual screening against COVID-19. Brief Bioinform., 22(2):1053-1064. doi:10.1093/bib/bbaa422.

Yerima, M. B.; Jodi, S. M.; Oyinbo, K.; Maishanu, H. M.; Farouq, A. A.; Junaidu,A. U. and Shinkafi, L. (2012). Effect of neem extracts (Azadirachta indica) on bacteria isolated from adult mouth. Nigerian Journal of Basic and Applied Sciences, 20(1):64-67.

Yi, L.; Li, Z. and Yuan, K. (2004). Small molecules blocking the entry of severe acute respiratory syndrome coronavirus into host cells. J Virol., 78(20):11334-11339.

Yoo, E. S.; Choo, G. S.; Kim, S. H.; Woo, J. S.; Kim, H. J.; Park, Y. S. and Jung, J. Y. (2019). Antitumor and apoptosis-inducing effects of piperine on human melanoma cells. Anticancer Research, 39(4):1883-1892.

Zeng, Y.; Pu, X.; Du, J.; Yang, X.; Li, X.; Mandal, M. S.N. and Yang, J. (2020). Molecular mechanism of functional ingredients in barley to combat human chronic diseases. Oxidative Medicine and Cellular Longevity, pp:1-26.

Zhang, T.; Wu, Z.; Du, J.; Hu, Y.; Liu, L. and Yang, F. (1992). Anti-Japaneseencephalitis-viral effects of kaempferol and daidzin and their RNAbinding characteristics. PLoS One , 7(1):e30259.

Zheng, G.Q.; Kenney, P.M. and Lam, L.K. (1992). Sesquiterpenes from clove (Eugenia caryophyllata) as potential anticarcinogenic agents. J.Nat. Prod., 55:999-1003.

Nupur Mehrotra, Sara A. Khan and Kaustubh Jadhav (2021). Potential herbs as therapeutic agents for COVID-19: In silico studies. Ann. Phytomed., Volume10, Special Issue2 (COVID-19): S98-S110. http://dx.doi.org/10.54085/ ap.covid19.2021.10.2.11 